\title{
Cohesin Irr1/Scc3 is likely to influence transcription in Saccharomyces cerevisiae via interaction with Mediator complex
}

\author{
Agata Cena, Marek Skoneczny, Anna Chełstowska, Piotr Kowalec, Renata Natorff \\ and Anna Kurlandzka ${ }^{\bowtie}$
}

Institute of Biochemistry and Biophysics, Polish Academy of Sciences, Warsaw, Poland

\begin{abstract}
The evolutionarily conserved proteins forming sister chromatid cohesion complex are also involved in the regulation of gene transcription. The participation of SA2p (mammalian ortholog of yeast Irr1p, associated with the core of the complex) in the regulation of transcription is already described. Here we analyzed microarray profiles of gene expression of a Saccharomyces cerevisiae irr1-1/IRR1 heterozygous diploid strain. We report that expression of 33 genes is affected by the presence of the mutated Irr1-1p and identify those genes. This supports the suggested role of Irr1p in the regulation of transcription. We also indicate that Irr1p may interact with elements of transcriptional coactivator Mediator.
\end{abstract}

Key words: sister chromatid cohesion, transcription, Saccharomyces cerevisiae

Received: 28 February, 2013; revised: 02 April, 2013; accepted: 18 April, 2013; available on-line: 31 May, 2013

\section{INTRODUCTION}

Sister chromatid cohesion complex has initially been characterized as a set of four evolutionarily conserved proteins essential for chromosome segregation (Guacci et al., 1997; Michaelis et al., 1997). It comprises three core subunits called cohesins: Mcd1/Scc1, Smc1 and Smc3, and an accesory protein Irr1/Scc3 (yeast nomenclature). For recruiting cohesin to the chromosome two proteins Scc2 and Scc4 (also evolutionarily conserved) are necessary (Ciosk et al., 2000; Tomonaga et al., 2000). The first years of cohesion research focused on its function in chromosome segregation and chromosome condensation, where cohesin has been proposed to facilitate chromatin loop formation (Guacci et al., 1997, Novak et al., 2008).

However, it has also been noticed that mutations in genes encoding cohesins Smc1 and Smc3 of S. cerevisiae cause a loss of function of the boundary element surrounding the HMR silent-mating-type loci (Donze et al., 1999), which indicated a role of these proteins in transcription regulation. Further characterization of Drosophila Nipped B protein, a homolog of yeast Scc2, also indicated its role in regulation of gene expression (Rolins et al., 1999, Dorsett, 2009). Similarly, a closer examination of SA2p, a mammalian homolog of yeast Irr1p, indicated that it may act as a transcriptional co-activator by interacting with transcription factors (Lara-Pezzi et al., 2004). Subsequently, it has been evidenced that cohesin regulates transcription via multiple mechanisms (for review: Dorsett, 2011). Cohesin facilitates looping out of DNA and communication between transcriptional enhancers and gene promoters, at sites that bind CCCTC-binding factor (CTCF) (Kagey et al., 2010; Cien et al., 2011; Hadjur et al., 2009; Hou et al., 2010). There is also evidence for CTCF-independent cohesin recruitment to various genomic regions, which suggests another mechanism of gene regulation (Kagey et al., 2010, Schmidt et al., 2010, Zeng et al., 2009). In Drosophila and in mouse embryonic stem cells cohesin represses many genes, acting in concert with the Polycomb group (PcG) repressor proteins, especially these which control growth and development (Dorsett, 2011, Kagey et al., 2010, Schaaf et al., 2009).

Genome-wide mapping showed that cohesin binds to the chromosome at discrete loci both in yeast and vertebrate cells, although the exact mechanisms of cohesin recruitment in yeast and humans may differ (Glynn et al., 2004; Lengronne et al., 2004; Parelho et al., 2008; Rubio et al., 2008; Wendt et al., 2008). In yeast, most cohesinbinding sites correspond to locations where genes are transcribed in a convergent orientation, and are likely to be linked with transcript termination (Glynn et al. 2004; Lengronne et al. 2004, Gullerova \& Proudfoot 2008). During yeast meiosis chromosomal binding of cohesin is sufficient for target-gene activation. The protein Scc2 activates the expression of the gene REC8 (encoding meiotic equivalent of Mcd1p) by recruiting cohesin to an upstream region in a position-dependent manner (Lin et al., 2011A, Lin et al., 2011B). Surprisingly, conditional inactivation of the most thoroughly characterized cohesin Mcd1 was sufficient to significantly alter transcriptional profiles of many genes which had highly related functions (Skibbens et al. 2010).

Understanding cohesin function in transcription regulation is of clinical importance since mutations in cohesion pathways cause developmental abnormalities such as Cornelia de Lange Syndrome, Roberts Syndrome/ SC-Phocomelia, and Rothman-Thompson Syndrome (Skibbens 2009, Gartenberg 2009, Liu et al., 2009, Dorsett, 2007). Subtle mutations in cohesin components that apparently do not affect the chromosomal cohesion can alter the transcriptome and have been associated with diseases (Liu et al., 2009).

Accumulating evidence on the participation of SA2p (a mammalian ortholog of the yeast Irr1p) in the regulation of transcription (Wendt et al., 2008; Parelho et al., 2008; Degner et al., 2008) prompted us to verify the role of Irr1p in this process in yeast. We used a well-characterized irr1-1/IRR1 yeast heterozygous diploid strain. The mutation irr1-1 is lethal in the haploid but the dip-

e-mail: ania218@ibb.waw.pl

Abbreviations: HU, hydroxyurea; MMS, methyl methane sulfonate 
loid irr1-1/IRR1 bears two types of the Irr1 protein: one wild-type and one with the F658G substitution. Such strain mimics, to some extent, a mammalian somatic cell with a cohesin defect (Cena et al., 2007; 2008, 2012). We analyzed microarray profiles of RNA expression of the irr1-1/IRR1 strain and report here the identity of those genes whose regulation was affected by the presence of the mutated Irr1-1p. Moreover, by performing two-hybrid study, we identified a putative indirect link between Irr1p cohesin and elements of the Mediator, a key regulator of eukaryotic transcription, connecting activators and repressors bound to regulatory DNA elements with RNA polymerase II (Boube et al., 2002, Kornberg, 2005, Conaway et al., 2005). This finding should be helpful in characterizing the gene regulatory networks involving cohesin.

\section{MATERIALS AND METHODS}

Strains, media and general methods. Yeast strains used in the present study were isogenic with the strain W303. Escherichia coli XL1-Blue MRF0 (Stratagene) was used for molecular manipulations. Yeast culture media were prepared as described (Rose et al., 1990). YPD contained 1\% Bacto-yeast extract, 2\% Bacto-peptone and $2 \%($ all w/v) glucose. SD contained $0.67 \%$ yeast nitrogen base without amino acids (Difco) and $2 \%$ glucose.

Microarrays. For microarray analyses yeast cells were cultivated in YPD complete medium to a density of $5 \times 10^{6}$ cells $/ \mathrm{ml}$. The resulting cultures were harvested by centrifugation and RNA extracted from the pellets using hot acid phenol procedure. RNA quality was assessed by 260/280 and 260/230 OD ratios. Fluorescently labeled cDNA probes were prepared using Superscript II RT (Fermentas) reverse transcriptase and Cyanine-3- or Cyanine-5-dCTP (Perkin Elmer). Two-color hybridizations were run in quadruplicates with dye swap between duplicates of the same variant. Labeled samples were hybridized to yeast oligonucleotide microarrays (Transcriptome Platform, Ecole Normale Superieure, Paris), spotted in duplicate with Operon v 2.2 60-mer oligo set representing 6,388 ORFs and controls. Axon GenePix 4000B scanner and GenePix software (Molecular Devices) were used for scanning and feature extraction. Statistical evaluation employing Student's $t$-test was performed with Acuity software (Molecular Devices). A $p$ value lower than 0.05 was accepted as significant. Upregulation of particular gene expression level in either variant was inferred from a positive $\log _{2}$ ratio value.

Determination of mRNA levels and RT-PCR. Total RNA was isolated from yeast cells using the RNeasy Mini Kit (QIAGEN, Germany). Reverse transcription (RT) was performed in duplicate using the QuantiTect Reverse Transcription Kit (QIAGEN), according to the manufacturer's recommendations. qPCR amplification was performed using a LightCycler 1.5 and LightCycler FastStart DNA Master SYBR Green I (Roche Diagnostics $\mathrm{GmbH}$, Germany) according to the manufacturer's instructions. The Pfaffl model (Pfaffl, 2001) and the relative expression software tool (REST-384 C) (Pfaffl et al., 2002) were used to estimate the changes in relative mRNA levels. Data normalization was carried out against the $35 \mathrm{~S}$ rRNA transcript. The sequences of all primers and qPCR amplification parameters are available upon request.

Two-hybrid analysis. Two independent two-hybrid studies were carried out. In the first assay Swc4-24 bait protein was fused to the Gal4p DNA binding domain on pGBKT7 plasmid (Clontech). The protein Swc4-24 consists of 269 amino acids and is devoid of 24 C-terminal amino acids (Micialkiewicz \& Chelstowska, 2008). The procedure was done in our laboratory, according to protocols described by Vojtek et al. (1997), by sequential transformation using the genomic library of FromontRacine et al., (1997). Direct two-hybrid analyses were done with cotransformed haploid cells. The host strain for the two-hybrid studies was PJ69-4 $\alpha$ (James et al., 1996). In the second assay, performed by Dualsystems Biotech AG (Switzerland), the bait LexA-Swc4-24p was used, and the whole procedure was carried out according to the company protocols.

\section{RESULTS AND DICSUSSION}

Previous work from our laboratory showed that the heterozygous diploid irr1-1/IRR1 exhibits irregularities in mitotic and meiotic divisions, chromosome segregation errors, disturbances in segregation of nuclei, and in cytokinesis. However, the chromosome segregation errors of mitotically dividing irr1-1/IRR1 cells, which did not lead to cell lethality, were increased only to $9.4 \%$ compared to $0.2 \%$ in the control IRR $1 /$ IRR 1 strain. On the other hand, a majority of mutant cells displayed phenotypic defects in cell wall stability and increased $\mathrm{HU}$ (hydroxyurea) and MMS (methyl methane sulfonate) sensitivity (Cena et al., 2007, 2008). Such a spectrum of defects suggested that the growth defects of the mutant could result from changes of transcription, manifested in all cells, rather than from errors in chromosome segregation. Transcription could be affected due to the pool of mutated Irr1-1p present in the diploid irr1-1/IRR1 at a level similar to the wild-type Irr1p.

To verify this assumption we compared transcriptomes of IRR1/IRR1 and irr1-1/IRR1 strains by ge-

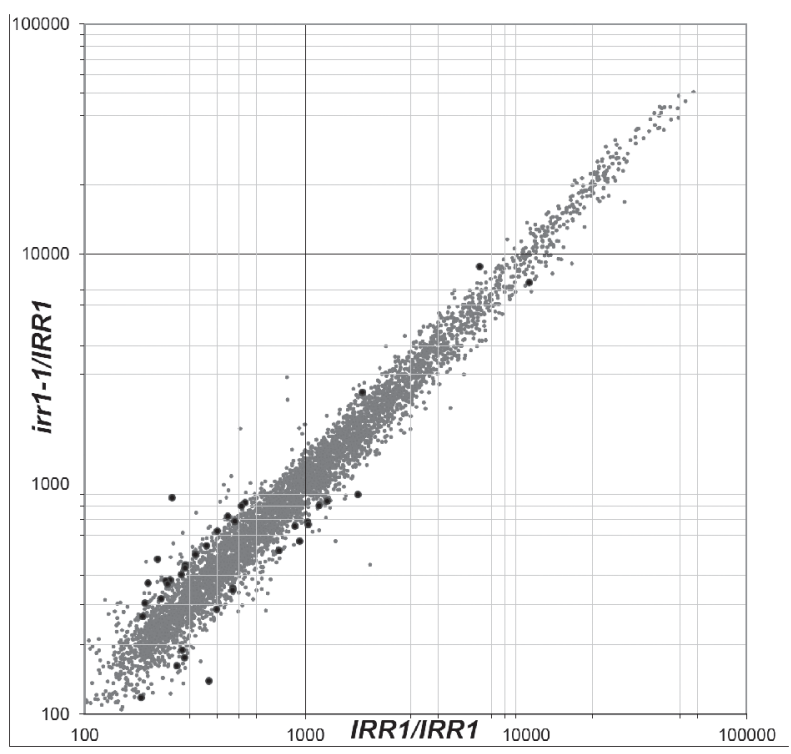

Figure 1. Scatter plot summarizing the transcriptome data obtained in this study.

Each point on the plot represents the expression data for a single gene in irr1-1/IRR1 heterodiploid compared to IRR1/IRR1 wild-type. Data were Lowess normalized and averaged across all microarray experiments. Smaller gray dots denote genes for which significant fluorescence values were obtained in at least two out of six microarray experiments. Larger black dots correspond to genes with Log Ratio of expression $>0.5$ or $<-0.5$ and $p$-value $<0.05$. $X$ axis: fluorescence intensity for IRR1/IRR 1 wild-type, $Y$ axis: fluorescence intensity for irr1-1//RR1 heterodiploid. 
Table 1. Thirty-three genes showing altered expression in response to the presence of mutated Irr1-1p cohesin.

Bold - gene/ORF up regulated, regular — down regulated.

\begin{tabular}{|c|c|c|c|c|}
\hline Common name & ORF & Chromosome & $\log R$ & Fold change \\
\hline AAD6 & YFL056C & VI & -0.7 & 1.6 \\
\hline AMS1 & YGL156W & VII & 1.0 & 2.0 \\
\hline BNA4 & YBL098W & II & -0.7 & 1.6 \\
\hline CMK2 & YOL016C & $X V$ & 0.6 & 1.5 \\
\hline CRC1 & YOR100C & $X V$ & 0.8 & 1.7 \\
\hline DCS2 & YOR173W & $X V$ & 0.7 & 1.6 \\
\hline$D E F 1$ & YKL054C & $\mathrm{XI}$ & -0.7 & 1.6 \\
\hline ENP1 & YBR247C & II & -0.5 & 1.4 \\
\hline GLC3 & YEL011W & V & 1.2 & 2.3 \\
\hline HAP4 & YKL109W & $\mathrm{XI}$ & -0.7 & 1.6 \\
\hline HXK1 & YFR053C & VI & 1.9 & 3.7 \\
\hline$M A E 1$ & YKL029C & $X I$ & -0.6 & 1.5 \\
\hline MAK5 & YBR142W & II & -0.6 & 1.5 \\
\hline MEC1 & YBR136W & II & -0.6 & 1.5 \\
\hline$M S I 1$ & YBR195C & II & -0.5 & 1.4 \\
\hline NRD1 & YNL251C & XIV & -0.6 & 1.5 \\
\hline PEP12 & YOR036W & XV & 0.5 & 1.4 \\
\hline $\mathrm{PHO} 3$ & YBR092C & II & -0.5 & 1.4 \\
\hline PYK2 & YOR347C & $X V$ & 0.7 & 1.6 \\
\hline PWP2 & YCR057C & III & -0.6 & 1.5 \\
\hline RKM3 & YBR030W & II & -0.6 & 1.5 \\
\hline RTC3 & YHR087W & VIII & 2.3 & 4.9 \\
\hline SPT7 & YBR081C & II & -0.5 & 1.4 \\
\hline SPS18 & YNL204C & XIV & -0.8 & 1.7 \\
\hline STF2 & YGR008C & VII & 0.9 & 1.9 \\
\hline SWC3 & YAL011W & I & -0.5 & 1.4 \\
\hline \multirow[t]{7}{*}{ YBP1 } & YBR216C & II & -0.5 & 1.4 \\
\hline & YBR063C & II & -1.0 & 2.0 \\
\hline & YBR074W & II & -0.5 & 1.4 \\
\hline & YGR079W & VII & -0.6 & 1.5 \\
\hline & YGR149W & VII & 0.5 & 1.4 \\
\hline & YKL151C & XI & 0.7 & 1.6 \\
\hline & YNL134C & XIV & -0.9 & 1.9 \\
\hline
\end{tabular}

nome-wide microarray expression analysis. An overall view on the gene expression changes in the irr1-1/ IRR1 strain is given in Fig. 1. We limited our analyses to those genes whose expression level in the mutant was significantly $(p<0.05)$ increased or decreased 1.4 -fold or more, relative to wild-type cells. This was represented by microarray signal Log Ratio $(\log R)\left|\log _{2} R\right|>0.5$. As a result we identified with high confidence 33 loci exhibiting highly reproducible and significant changes common to all data sets, which are summarized in Table 1 . To validate microarray data we verified a random sample of five genes by realtime quantitative RT-PCR. We analysed the level of transcription of RTC3, HXK1, DEF1, YER079W and YBR063C, and normalized the data to $35 \mathrm{~S}$ ribosomal RNA (rRNA), a housekeeping gene. The qRT-PCR results (not shown) were in agreement with the microarray results.
Among the 33 genes identified by microarray analysis 11 are localized on chromosome II. Ten of them, upregulated at the 1.4-2.0 fold level, are spread along the right arm and are not clustered [RKM3 (YBR030W), YBR074W, MEC1 (YBR136W), MAK5 (YBR142W), YBR063C, SPT7 (YBR081C), PHO3 (YBR092C), MSI1 (YBR195C), YBP1 (YBR216C), ENP1 $(Y B R 247 C)]$. Thus, the changes of their transcription rather did not result from a coordinated induction of adjacent loci. Moreover, we did not find binding sites for a common transcription factor in their promoters (http://rsat. ulb.ac.be/rsat/). However, the fact that they are localized on the same arm of one chromosome suggests that changes of transcription could result from a rearrangement of the chromosome. Gene ontology analysis does not show any direct relations among the proteins encoded by these genes. They are involved in RNA processing, transcription (directly or through interactors), chromatin assembly, and protein modifications. The transcription of one gene (BNA4) localized on the left arm is downregulated. The five affected genes localized on chromosome XV [PEP12 (YOR036W), DCS2 (YOR173W), CMK2 (YOL016C), CRC1 (YOR100C), PYK2 (YOR 347C)] also seem unrelated in function. As above, we did not find binding sites for a common transcription factor in their promoters. They are not clustered, although they are all upregulated at a similar level (1.4-1.6 fold). The protein encoded by PEP12 is involved in vesicular transport. $\mathrm{Cmk} 2 \mathrm{p}$ is a calmodulin-dependent protein kinase which may play a role in stress response, Crc1p is a mitochondrial inner membrane carnitine transporter, and PYK2 encodes pyruvate kinase. What is interesting, a regulatory protein Dcs2 was identified among factors which allow cells to tolerate the adverse effects of aneuploidy (Torres et al., 2010).

Six other genes localized on various chromosomes encode proteins involved, at least to some extent, in carbohydrate metabolism (RTC3, GLC3, HXK1, AMS1, PYK2 and MAE1). Changes in transcription levels of RTC3, GLC3, HXK1 and AMS1 may, to some extent, be related to the aberrated cell-wall phenotypes of irr 1 1/IRR1 strain. These genes, the transcription of which is induced, are localized on various chromosomes. Transcriptomic studies indicated the relevance of RTC3-encoded protein to transcription control during the response to high sugar and stress conditions, or a role in the stationary phase (Gasch et al., 2000, Jimenez-Marti et al., 2011). However, the protein has also been implicated in the cell wall integrity pathway, although this function has not been studied in detail (Garcia et al., 2009). GLC3 encodes $1,4-\alpha$-glucan branching enzyme involved in the synthesis of glycogen, a major intracellular reserve polymer formed upon limitation of carbon, nitrogen, phosphorus or sulfur. The branching is important for glycogen function because both its synthesis and degradation occur from the nonreducing ends of the $\alpha-1,4$ chains (Roach et al., 2001). The link of the GLC3-encoded protein to the cell wall integrity may also be explained by a general function of glycogen in the basal matrix where it binds cell wall $\beta$-1,3-glucans and holds other carbohydrate components covalently linked to the cell wall (Arvin- 


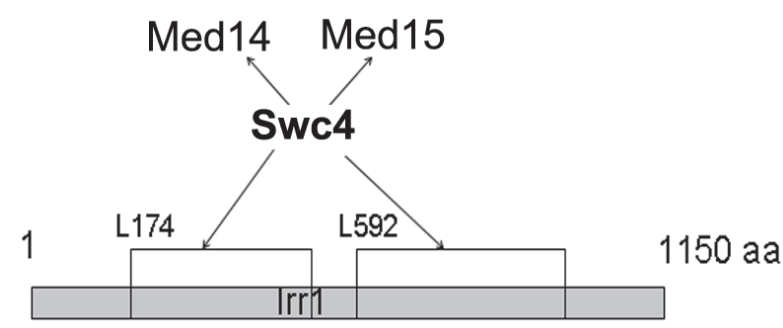

Figure 2. Swc4p, an element of NuA4-HAT, interacts with the Irr1/Scc3 cohesin and two elements of the Mediator complex. The interaction between Swc4p and Irr1p has been detected in the yeast two-hybrid system. Two different fragments of the Irr1p, one starting from L174 and the second starting from L592, were identified. Independently, interactions of Swc4p with Med14p and Med15p subunits of the Mediator were found.

dekar \& Patil 2002). A change in the HXK1 transcript level may constitute another link to the cell wall phenotypes. Hexokinase Hxk1p, together with the isoenzyme Hxk2p and glucokinase Glk1p, catalyzes phosphorylation of glucose. A targeted proteomics approach clustered Hxk2 in the glycolytic branch, Glk1 — with tricarboxylic acid cycle proteins, and Hxk1 - with the 1,4- $\alpha$-glucan branching enzyme Glc3p, discussed above (Costenoble et al., 2011). Both Glk1 and Hxk1 have been speculated to be involved in glycogen storage rather than in the regular glycolytic path involving Hxk2 (Ihmels et al., 2004). Moreover, HXK1 was also identified among genes induced by cell wall perturbation and it was upregulated by calcofluor white, a cell-wall damaging agent (Boorsma et al., 2004). AMS1 encodes vacuolar alpha mannosidase involved in free oligosaccharide (fOS) degradation. The biological relevance of this process is poorly understood. It has been shown that in budding yeast almost all fOSs are formed from misfolded glycoproteins. However, an up-regulation of Ams1 activity was apparent for cells treated with cell-wall-perturbing agents, which may constitute a possible link between the catabolism of fOSs and cell wall stress (Hirayama \& Suzuki, 2011).

Another group comprised genes whose transcription was significantly decreased in the irr1-1/IRR1 strain. These are four genes involved in the regulation of transcription or chromatin organization HAP4, SPT7, MSI1 and SWC3. The decrease of the level of HAP4 (exerts an effect on respiratory gene expression) may reflect minute differences in the metabolic status between the mutant and control strain. Genes SPT7 and MSI1 are both localized on the right arm of chromosome II and are separated by a distance of about $13000 \mathrm{bp}$. The similar level of down-regulation of both genes may be an example of the spreading of changes in chromatin structure to neighboring domains elicited by cohesin, postulated by Skibbens et al. (2010).

The protein encoded by SWC3 is a component of the SWR1 complex, which exchanges histone variant H2AZ (Htz1p) for chromatin-bound histone H2A (Bao \& Shen, 2011). This complex shares some subunits with NuA4 complex - a histone acetyltransferase (NuA4HAT), which plays fundamental roles in regulating gene expression (Brown et al., 2000; Narlikar et al., 2002). It is believed that the NuA4-HAT and SWR1 complexes may, to some extent, have overlaping functions (Lin et al., 2008, Lu et al., 2009). Swc3p is not a subunit of NuA4-HAT, but it was identified as an interactor of a few proteins assigned to this complex.

While working on the putative role of Irr1p in transcription, we simultaneously carried out a two-hybrid as- say to look for new physical interactions of Swc4p of the NuA4-HAT complex (Krogan et al., 2003). In this assay we identified Irr1p as one such interactor. Two Swc4pinteracting fragments of Irr1p comprised 319 and 379 aminoacids, respectively, the first starting from leucine 174, the second from leucine 592. Moreover, the same screen idenified Swc4p interaction with two components of a multisubunit transcriptional coactivator complex - Mediator. Mediator interacts directly with a number of transcription factors to facilitate RNA polymerase II recruitment to target genes. The subunit Med14/Rgr1 (YLR071c) was identified three times, and the subunit Med15/Gal11 (YOLO51w) — two times (summarized in Fig. 2).

It has been found that in murine embryonic stem cells Mediator and the cohesin complex physically and functionally connect the enhancers and core promoters of active genes (Kagey et al., 2010). Elements identified in that screen comprised cohesins Smc1, Smc3, Nipbl (a homolog of fungal Scc2) and SA2/Stag2 (one of two mitotic mammalian equivalents of Irr1p) and subunits Med1, Med12 and Med15-17 of Mediator. Subsequent findings confirmed the interactions between Mediator and cohesins in the regulation of gene expression (Dorsett, 2011, Prenzel et al., 2012). Our data reported here are insufficient to conclude that in yeast Swc4p mediates an interaction of Irr1p with Mediator, since we did not show that Swc4p can interact with its partners simultaneously. However, it seems plausible that, similarly to higher eukaryotes, Irr1p may play a role in regulating transcription via Mediator.

In conclusion, the data presented in this report suggest that the phenotypes of the heterozygous diploid irr1-1/IRR1 unrelated to chromosome segregation defect could result from changes in expression of individual genes. The aberrated cell-wall phenotypes could be related to changes of expression of RTC3, GLC3, HXK1 and AMS1. The increased HU and MMS sensitivity could result from decreased levels of transcription of four genes involved in the regulation of transcription itself or in chromatin organization: HAP4, SPT7, MSI1 and SWC3. These observations support the suggested role of Irr1 protein in the regulation of transcription. Moreover, for the first time in yeast we indicate for a link between the cohesin and elements of Mediator. These data may contribute to better understanding of the role of Irr1p in transcription.

\section{Acknowledgements}

We thank Drs: Arkadiusz Miciałkiewicz, Marzena Sieńko and Anna Wójcicka for help in performing and discussing experiments.

This work was supported in part by the Ministry of Science and Higher Education, grants 2 P04C01130 and N N303 456838.

\section{REFERENCES}

Arvindekar AU, Patil NB (2002) Glycogen-a covalently linked component of the cell wall in Saccharomyces cerevisiae. Yeast 19: 131-139.

Boorsma A, Nobel HD, Riet BT, Bargmann B, Brul S, Hellingwerf KJ, Klis FM (2004) Characterization of the transcriptional response to cell wall stress in Saccharomyces cerevisiae. Yeast 21: 413-427.

Bao Y, Shen X (2011) SnapShot: Chromatin remodeling: INO80 and SWR1. Cell 144: 158-158.e2.

Boube M, Joulia L, Cribbs DL, Bourbon HM (2002) Evidence for a mediator of RNA polymerase II transcriptional regulation conserved from yeast to man. Cell 110: 143-151.

Brown CE, Lechner T, Howe L, Workman JL (2000) The many HATs of transcription coactivators. Trends Biochem Sci 25: 15-19. 
Cena A, Orlowski J, Machuła K, Fronk J, Kurlandzka A (2007) Substitution F659G in the Irr1p/Scc3p cohesin influences the cell wall of Saccharomyces cerevisiae. Cell Struct Funct 32: 1-7.

Cena A, Kozłowska E, Płochocka D, Grynberg M, Ishikawa T, Fronk J, Kurlandzka A (2008) The F658G substitution in Saccharomyces cerevisiae cohesin Irr1/Scc3 is semi-dominant in the diploid and disturbs mitosis, meiosis and the cell cycle. Eur J Cell Biol 87: 831-844.

Cena A, Kowalec P, Płochocka D, Kurlandzka A (2012) Irr1/Scc3 Cohesin interacts with $\operatorname{Rec} 8$ in meiotic prophase of Saccharomyces cerevisiae. OJGen 2: 1-6.

Ciosk R, Shirayama M, Shevchenko A, Tanaka T, Toth A, Shevchenko A, Nasmyth K (2000). Cohesin's binding to chromosomes depends on a separate complex consisting of Scc2 and Scc4 proteins. Mol Cell 5: 243-254.

Conaway RC, Sato S, Tomomori-Sato C, Yao T, Conaway JW (2005) The mammalian Mediator complex and its role in transcriptional regulation. Trends Biochem Sci 30: 250-255.

Costenoble R, Picotti P, Reiter L, Stallmach R, Heinemann M, Sauer U, Aebersold R (2011) Comprehensive quantitative analysis of central carbon and amino-acid metabolism in Saccharomyces cerevisiae under multiple conditions by targeted proteomics. Mol Syst Biol 7: 464.

Degner SC, Wong TP, Jankevicius G, Feeney AJ (2008) Cutting edge: developmental stage-specific recruitment of cohesin to CTCF sites throughout immunoglobulin loci during B lymphocyte development. I Immunol 182: 44-48.

Donze D, Adams CR, Rine J, Kamakaka RT (1999) The boundaries of the silenced HMR domain in Saccharomyces cerevisiae. Genes Dev 13: 698-708.

Fromont-Racine M, Rain JC, Legrain P (1997) Toward a functional analysis of the yeast genome through exhaustive two-hybrid screens. Nat Genet 16: 277-282.

Garcia R, Rodriguez-Pena JM, Bermejo C, Nombela C, Arroyo J (2009) The high osmotic response and cell wall integrity pathways cooperate to regulate transcriptional responses to zymolyase-induced cel wall stress in Saccharomyces cerevisiae. J Biol Chem 284: 10901-10911.

Gartenberg M (2009) Heterochromatin and the cohesion of sister chromatids. Chromosome Res 17: 229-238.

Gasch AP, Spellman PT, Kao CM, Carmel-Harel O, Eisen MB, Storz G, Botstein D, Brown PO (2000) Genomic expression programs in the response of yeast cells to environmental changes. Mol Biol Cell 11: 4241-4257.

Glynn EF, Megee PC, Yu HG, Mistrot C, Unal E, Koshland DE, DeRisi JL, Gerton JL (2004) Genome-wide mapping of the cohesin complex in the yeast Saccharomyces cerevisiae. PLoS Biol 2: E259.

Guacci V, Koshland D, Strunnikov A (1997) A direct link between sister chromatid cohesion and chromosome condensation revealed through the analysis of MCD1 in S. cerevisiae. Cell 91: 47-57.

Gullerova M, Proudfoot NJ (2008) Cohesin complex promotes transcriptional termination between convergent genes in $S$. pombe. Cell 132: 983-995

Dorsett D (2007) Roles of the sister chromatid cohesion apparatus in gene expression, development and human syndromes. Chromosoma 116: $1-13$.

Dorsett D (2009) Cohesin, gene expression and development: lessons from Drosophila. Chromosome Res 17: 185-200.

Dorsett D (2011) Cohesin: genomic insights into controlling gene transcription and development. Curr Opin Genet Dev 21: 199-206.

Hadjur S, Williams LM, Ryan NK, Cobb BS, Sexton T, Fraser P, Fisher AG, Merkenschlager M (2009) Cohesins form chromosoma cis-interactions at the developmentally regulated IFNG locus. Nature 460: $410-413$

Hirayama H, Suzuki T (2011) Metabolism of free oligosaccharides is facilitated in the och1 $\Delta$ mutant of Saccharomyces cerevisiae. Glycobiology 21: 1341-1348.

Hou C, Dale R, Dean A (2010). Cell type specificity of chromatin organization mediated by CTCF and cohesin. Proc Natl Acad Sci USA 107: 3651-3656.

Ihmels J, Levy R, Barkai N (2004) Principles of transcriptional control in the metabolic network of Saccharomyces cerevisiae. Nat Biotechnol 22 86-92.

James P, Halladay J, Craig EA (1996) Genomic libraries and a host strain designed for highly efficient two-hybrid selection in yeast. Genetics 144: 1425-1436.

Jimenez-Marti E, Zuzuarregui A, Gomar-Alba M, Gutierrez D, Gil C, del Olmo M (2011) Molecular response of Saccharomyces cerevisiae wine and laboratory strains to high sugar stress conditions. Int J Food Microbiol 145: 211-220.

Kagey MH, Newman JJ, Bilodeau S, Zhan Y, Orlando DA, van Berkum NL, Ebmeier CC, Goossens J, Rahl PB, Levine SS, Taatjes DJ, Dekker J, Young RA (2010) Mediator and cohesin connect gene expression and chromatin architecture. Nature 467: 430-435.

Kornberg RD (2005) Mediator and the mechanism of transcriptional activation. Trends Biochem Sci 30: 235-239.

Kobor MS, Venkatasubrahmanyam S, Meneghini MD, Gin JW, Jennings JL, Link AJ, Madhani HD, Rine J (2004) A protein complex containing the conserved Swi2/Snf2-related ATPase Swr1p deposits histone variant H2A.Z into euchromatin. PLoS Biol 2: E131.

Krogan NJ, Keogh MC, Datta N, Sawa C, Ryan OW, Ding H, Haw RA, Pootoolal J, Tong A, Canadien V, Richards DP, Wu X, Emili A, Hughes TR, Buratowski S, Greenblatt JF (2003) A Snf2 family ATPase complex required for recruitment of the histone $\mathrm{H} 2 \mathrm{~A}$ variant Htz1. Mol Cell 12: 1565-1576.

Lara-Pezzi E, Pezzi N, Prieto I, Barthelemy I, Carreiro C, Martinez A, Maldonado-Rodriguez A, Lopez-Cabrera M, Barbero JL (2004) Evidence of a transcriptional co-activator function of cohesin STAG/ SA/Scc3. I Biol Chem 279: 6553-6559.

Lengronne A, Katou Y, Mori S, Yokobayashi S, Kelly GP, Itoh T, Watanabe Y, Shirahige K, Uhlmann F (2004) Cohesin relocation from sites of chromosomal loading to places of convergent transcription. Nature 430: 573-578.

Lin YY, Qi Y, Lu J, Pan X, Yuan DS, Zhao Y, Bader JS, Boeke JD (2008) A comprehensive synthetic genetic interaction network governing yeast histone acetylation and deacetylation. Genes Dev 22: 2062-2074.

Lin W, Wang M, Jin H, Yu HG (2011A) Cohesin plays a dual role in gene regulation and sister-chromatid cohesion during meiosis in Saccharomyces cerevisiae. Genetics 187: 1041-1051.

Lin W, Jin H, Liu X, Hampton K, Yu HG (2011B) Scc2 regulates gene expression by recruiting cohesin to the chromosome as a transcriptional activator during yeast meiosis. Mol Biol Cell 22: 1985-1996.

Liu J, Zhang Z, Bando M, Itoh T, Deardorff MA, Clark D, Kaur M, Tandy S, Kondoh T, Rappaport E, Spinner NB, Vega H, Jackson LG, Shirahige K, Krantz ID (2009) Transcriptional dysregulation in NIPBL and cohesin mutant human cells. PLoS Biol 7: e1000119.

Lu PY, Levesque N, Kobor MS (2009) NuA4 and SWR1-C: two chromatin-modifying complexes with overlapping functions and components. Biochem Cell Biol 87: 799-815.

Michaelis C, Ciosk R, Nasmyth K (1997) Cohesins: chromosomal proteins that prevent premature separation of sister chromatids. Cell $\mathbf{9 1}$ $35-45$.

Micialkiewicz A, Chełstowska A (2008) The essential function of Sw$\mathrm{c} 4 \mathrm{p}$ - a protein shared by two chromatin-modifying complexes of the yeast Saccharomyces cerevisiae - resides within its N-terminal part. Acta Biochim Polon 55: 603-612.

Narlikar GJ, Fan HY, Kingston RE (2002) Cooperation between complexes that regulate chromatin structure and transcription. Cell 108: $475-487$.

Novak I, Wang H, Revenkova E, Jessberger R, Scherthan H, Hoog C (2008) Cohesin Smc1 $\beta$ determines meiotic chromatin axis loop organization. J Cell Biol 180: 83-90.

Parelho V, Hadjur S, Spivakov M, Leleu M, Sauer S, Gregson HC, Jarmuz A, Canzonetta C, Webster Z, Nesterova T, Cobb BS, Yokomori K, Dillon N, Aragon L, Fisher AG, Merkenschlager M (2008) Cohesins functionally associate with CTCF on mammalian chromosome arms. Cell 132: 422-433.

Pfaffl MW (2001) A new mathematical model for relative quantification in real-time RT-PCR. Nucleic Acids Res 29: e45.

Pfaffl MW, Horgan GW, Dempfle L (2002) Relative expression software tool (REST) for group-wise comparison and statistical analysis of relative expression results in real-time PCR. Nucleic Acids Res 30: e36.

Prenzel T, Kramer F, Bedi U, Nagarajan S, Beissbarth T, Johnsen SA (2012) Cohesin is required for expression of the estrogen receptoralpha (ESR1) gene. Epigenetics Chromatin 5: 13.

Roach PJ, Skurat AV, Harris RA (2001) Regulation of glycogen metabolism. In: Handbook of Physiology Section 7, Volume II The Endocrine pancreas and regulation of metabolism. II. Jefferson LS, Cherrington AD, eds, pp 609-647. Lippincott Company, Philadelphia.

Rubio ED, Reiss DJ, Weicsh PL, Disteche CM, Filippova GN, Baliga NS, Aebersold R, Ranish JA, Krumm A (2008) CTCF physically links cohesin to chromatin. Proc Natl Acad Sci US A 105: 8309-8314.

Tomonaga T, Nagao K, Kawasaki Y, Furuya K, Murakami A, Morishita J, Yuasa T, Sutani T, Kearsey SE, Uhlmann F, Nasmyth K, Yanagida M (2000) Characterization of fission yeast cohesin: essential anaphase proteolysis of Rad21 phosphorylated in the $\mathrm{S}$ phase. Genes Dev 14: 2757-2770.

Schaaf CA, Misulovin Z, Sahota G, Siddiqui AM, Schwartz YB, Kahn TG, Pirrotta V, Gause M, Dorsett D (2009) Regulation of the Drosophila enhancer of split and invected-engrailed gene complexes by sister chromatid cohesion proteins. PLOS ONE 4: e6202.

Schmidt D, Schwalie PC, Ross-Innes CS, Hurtado A, Brown GD, Carroll JS, Flicek P, Odom DT (2010) A CTCF-independent role for cohesin in tissue-specific transcription Genome Res 20: 578-588.

Skibbens RV (2009) Mechanisms of sister chromatid pairing. Int Rev Cell Mol Biol 269: 51-54.

Skibbens RV, Marzillier J, Eastman L (2010) Cohesins coordinate gene transcriptions of related function within Saccharomyces cerevisiae. Cell Cycle 9: 1601-1606.

Torres EM, Dephoure N, Panneerselvam A, Tucker CM, Whittaker CA, Gygi SP, Dunham MJ, Amon A (2010) Identification of aneuploidy-tolerating mutations cell 143: 71-83. 
Vojtek AB, Cooper JA, Hollenberg SM (1997) In The yeast two-bybrid system. Bartel PL, Fields S. eds, pp 29-42. Oxford University Press, New York.

Wendt KS, Yoshida K, Itoh T, Bando M, Koch B, Schirghuber E, Tsutsumi S, Nagae G, Ishihara K, Mishiro T, Yahata K, Imamoto F, Aburatani H, Nakao M, Imamoto N, Maeshima K, Shirahige K, Peters JM (2008) Cohesin mediates transcriptional insulation by CCCTC-binding factor. Nature 451:796-801.
Zeng W, de Greef JC, Chen YY, Chien R, Kong X, Gregson HC, Winokur ST, Pyle A, Robertson KD, Schmiesing JA, Kimonis VE, Balog J, Frants RR, Ball AR Jr, Lock LF, Donovan PJ, van der Maarel SM, Yokomori K (2009) Specific loss of histone H3 lysine 9 trimethylation and HP1gamma/cohesin binding at D4Z4 repeats is associated with facioscapulohumeral dystrophy (FSHD). PLoS Genet. 5: e1000559. 